\title{
Metabolic Factors in Obesity
}

\author{
Nádia Brito ${ }^{1}$, Margarida Fonseca ${ }^{1}$, Isabel Dinis ${ }^{2}$ and Alice Mirante ${ }^{2}$ \\ 'Pediatric Division and ${ }^{2}$ Endocrinology Unit, Hospital Pediátrico de Coimbra, Coimbra, Portugal
}

\begin{abstract}
Obesity has a rising prevalence in children and adolescents, affecting $30 \%$ of the paediatric population in Portugal. Leptin is an important hormone involved in the pathogenesis of obesity and has been under investigation as a risk marker for future complications.

Aims: 1. To evaluate the relation between serum leptin levels and body mass index (BMI) and height. 2. To compare leptin levels in obese and non-obese children. 3 . To evaluate the relation between leptin levels and insulin resistance index.

Methods: Cross-sectional study, using a sample of 70 obese children and a control group of 53 non-obese children. Obesity was defined as BMI standard deviation $>2$ for age and sex. In the obese group we assessed sex, age, BMI SDS and height SDS for age and sex, and serum levels of glucose, insulin and leptin. In the control group were obtained BMI SDS and height SDS for age and sex and leptin levels. Data were analysed using SPSS 12.

Results: The mean age of obese and non-obese children was $10.3 \pm 2.9$ versus $10.9 \pm 3.5$ years. In the obese group, $32(45.7 \%)$ were boys versus $18(31.0 \%)$ in the non-obese group. BMI SDS in the obese group was $3.12 \pm 0.60$ versus $0.20 \pm 0.99$ in the non-obese group (p $<0.001$ ). Leptin levels showed a positive correlation with BMI SDS $(r=0.69 ; p<0.001)$ and height SDS $(r=0.31 ; p<0.001)$. When comparing leptin levels between obese and non-obese groups, we found a significant difference in boys $(50.7 \pm 27.3$ versus $7.0 \pm 6.8$
\end{abstract}

Reprint address:

Alice Mirante

Unidade de Endocrinologia

Hospital Pediátrico de Coimbra

Avenida Bissaya Barreto

3000-076 Coimbra, Portugal

e-mail alice.mirante@gmail.com $\mathrm{ng} / \mathrm{ml} ; \mathrm{p}<0.001)$ and in girls $(57.6 \pm 25.5$ versus $16.5 \pm 10.3 \mathrm{ng} / \mathrm{ml} ; \mathrm{p}<0.001)$. In the nonobese group, leptin levels were lower in boys. This difference was not seen in the obese group. Leptin showed a positive correlation with insulin resistance index in boys $(r=0.45$, $p=0.05$ ), but not in girls.

Conclusions: This study has confirmed a positive correlation between leptin levels and BMI SDS. In obese children elevated leptin is associated with central resistance to its action. The positive correlation of leptin with insulin resistance index may suggest a major role of leptin in insulin resistance.

\section{KEY WORDS}

obesity, children, leptin, insulin resistance

\section{INTRODUCTION}

Obesity prevalence is rising dramatically in children and adolescents, and is becoming a worldwide problem. In Portugal as in other countries it affects $30 \%$ of the paediatric population and has profound public health consequences as a result of the relation with later life co-morbidities that are the primordial causes of death of the general population, such as stroke, heart disease and type 2 diabetes mellitus ${ }^{1,2}$.

Body weight is regulated by a complex feedback loop in which peripheral signals (leptin, adiponectin, ghrelin) report nutritional information to an integrator centre in the brain, the hypothalamus ${ }^{3}$.

Leptin is a peptide produced by adipocytes; it controls energy metabolism by suppressing food intake and stimulating energy expenditure. It is thought to be an important hormone involved in the pathogenesis of obesity and has been under investigation as a risk marker for future complications. Obesity is frequently associated with high 
plasma leptin concentrations and leptin resistance; many recent studies demonstrated a correlation between the concentration of leptin in serum and insulin resistance ${ }^{4,5}$.

The aims of the present study were to evaluate the relation between serum leptin levels and body mass index (BMI) and height, to compare leptin levels in obese and non-obese children, and to evaluate the relation between leptin levels and insulin resistance index.

\section{PATIENTS AND METHODS}

A descriptive cross-sectional study was performed, using a sample of 70 obese children attending the outpatient Clinic of Endocrinology at the Paediatric Hospital of Coimbra and a control group of 53 non-obese and healthy children also attending this clinic.

Age, sex, weight, height, BMI SDS and height SDS for age and sex and leptin levels were determined for all the children. In the obese group we also assessed serum levels of fasting glucose and insulin.

The same team of trained nurses performed all anthropometric measurements. Weight was measured to the nearest 0.1 kilogram and height to the nearest $0.1 \mathrm{~cm}$. Obesity was defined as BMI standard deviation $>2$ for age and sex. The insulin resistance index was obtained by the formula fasting glucose/insulin. It was considered insulin resistance when the index was greater than 2.7 $\mathrm{mmol} / \mathrm{mU}$.

The relationships between leptin levels and BMI, leptin and height were assessed by Pearson correlation coefficients (obese and control groups together, $n=123$ ). Leptin levels in obese and non-obese children were compared using t-test. In the obese group the relation between leptin levels and insulin resistance index was assessed by Pearson correlation coefficient.

Statistical analysis of the data was conducted using SPSS 12. The results are expressed as means \pm 2 SD. Statistical significance was set at $p$ $<0.05$.

\section{RESULTS}

Age and sex distribution in the two groups were not significantly different: mean age of the obese group was $10.3 \pm 2.94$ years versus $10.9 \pm$ 3.5 years in the non-obese group. The obese group had $32(45.7 \%)$ boys and the non-obese group had $18(31.0 \%)$ boys. Both BMI and height were significantly different between the two groups: BMI SDS in the obese group was $3.12 \pm$ 0.60 , and in the non-obese group $0.20 \pm 0.99$ (p $<0.001$ ); height- SDS was $1.18 \pm 1.38$ in the obese group and $0.05 \pm 1.62$ in the control group $(p<0.001$ ) (Table 1).

There was a positive correlation of leptin levels with BMI SDS (boys: $r=0.67, p<0.01$; girls: $r=0.72, p<0.01$ ) and height SDS (boys: $r=$ 0.38 , $\mathrm{p}<0.01$; girls: $\mathrm{r}=0.25, \mathrm{p}<0.05$ ) in both sexes (Fig. 1).

Leptin levels in obese boys were $50 \pm 27.3$ $\mathrm{ng} / \mathrm{ml}$ in contrast with non-obese boys who had leptin levels of $7.0 \pm 6.8 \mathrm{ng} / \mathrm{ml}(\mathrm{p}<0.001)$; in girls the levels were $57.6 \pm 25.5 \mathrm{ng} / \mathrm{ml}$ in the obese group versus $16.5 \pm 10.3 \mathrm{ng} / \mathrm{ml}$ in the nonobese group ( $p<0.001)$; these levels were significantly higher in the obese group than in the non-obese group in both sexes. Leptin was significant higher in girls than in boys in the nonobese group ( $p<0.05)$, but this significant difference is lost in the obese group (Table 2).

There was a positive correlation between leptin levels and insulin resistance index in boys $(r=0.45, p=0.05)$, but not in girls (Fig. 2).

\section{DISCUSSION}

In the present study positive correlations were found of leptin levels with BMI SDS and height SDS, and the correlation was stronger between leptin and BMI SDS, as expected. This is in agreement with known physiological pathways of energy control in humans, to signal energy availability, in which leptin rises with the increase of body fat ${ }^{5,6}$.

An interesting finding is that serum leptin was significantly higher in girls than in boys in the non-obese group. As reported in other studies, a strong sex difference exists at birth, with leptin 
TABLE 1

Sample and control descriptive data for age, sex, BMI SDS and height SDS

\begin{tabular}{lccc}
\hline & Obese & Non-obese & p \\
\hline n & 70 & 53 & \\
Age (years) & $10.3 \pm 2.9$ & $10.9 \pm 3.5$ & NS \\
Boys / Girls & $32 / 38$ & $18 / 35$ & NS \\
BMI SDS & $3.12 \pm 0.60$ & $0.20 \pm 0.99$ & 0.001 \\
Height SDS & $1.18 \pm 1.38$ & $0.05 \pm 1.62$ & 0.001 \\
\hline
\end{tabular}

TABLE 2

Leptin levels ( $\mathrm{ng} / \mathrm{ml})$ compared by group and by sex

\begin{tabular}{rccc}
\hline & Obese group & Non-obese group & p \\
\hline Boys' leptin levels & $50.7 \pm 27.3$ & $7.0 \pm 6.8$ & $<0.001$ \\
Girls' leptin levels & $57.6 \pm 25.5$ & $16.5 \pm 10.3$ & $<0.001$ \\
p & NS & 0.05 & \\
\hline
\end{tabular}
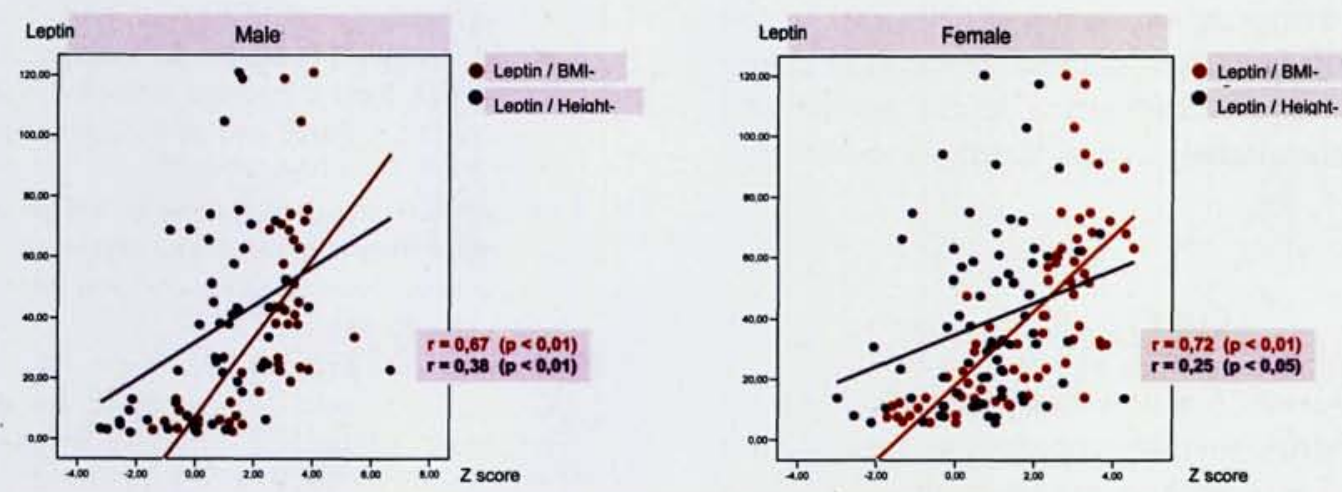

Fig. 1: Correlation between leptin and BMI SDS and height SDS in the 123 children by sex.
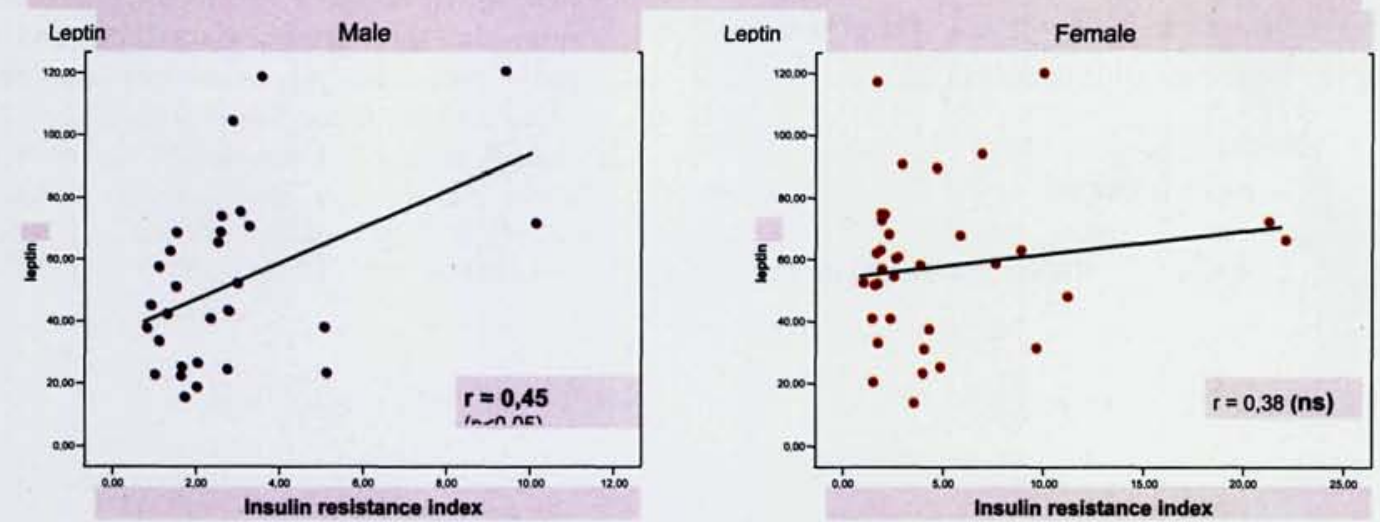

Fig. 2: Correlation between leptin and insulin resistance index by sex. 
concentrations being significantly higher in females than males and persisting through life ${ }^{7}$.

As demonstrated in many other studies, we found statistically significantly higher levels of leptin when comparing obese and non-obese children. These values may be related to a state of leptin resistance in obese children ${ }^{8-12}$.

The positive correlation between leptin levels and insulin resistance index in this study may suggest a role of leptin in insulin resistance. Insulin resistance related to obesity may be responsible for an increase in cytokines such as leptin; chronically increased insulin levels also concur with higher leptin. Recent reports have described an important correlation of leptin serum concentration with insulin resistance and other cardiovascular factors. Some described serum leptin as an independent risk factor for coronary heart disease and with significant association with metabolic syndromes ${ }^{5}$.

The main limitations of our study were the small sample size of the obese and control groups, and the cross-sectional design, which do not allow extrapolation of the conclusions to the general Portuguese population. More studies are needed to better characterize leptin profile and possible correlations with cardiovascular risk factors.

\section{CONCLUSIONS}

We are now in a new era in which there are many endocrinc-metabolic pathways that explain obesity and may be markers of co-morbidities of this disease. The concentration of leptin in serum is higher in obesity, correlates with insulin resistance, and may add important prognostic information for future cardiovascular risk.

\section{REFERENCES}

1. Farooqi IS, O'Rahilly S. Recent advances in the genetics of severe chilhood obesity. Arch Dis Child $2000 ; 83: 31-34$.

2. Monzavi R, Dreimane D, Geffner M, Braun S, Conrad $B$, Kiler M, Kaufman F. Improvement in risk factors for metabolic syndrome and insulin resistance in overweight youth who are treated with lifestyle intervention. Pediatrics 2006; 117;1111-1118.

3. Korner A, Bluher S, Kapellen T, Garten A, Klammt J, Kratzsch J, Kiess W. Obesity in childhood and adolescence: a review in the interface between adipocyte physiology and clinical challenges. Hormones 2005; 4 : 189-199.

4. Anahita H, Hossein F, Alireza M, Ramin I, Pantea E, Bagher. Metabolic syndrome and leptin concentrations in obese chlidren. Ind J Pediatr 2006; 73: 593-596.

5. Valle $M$, Martos R, Gascon F, Canete R, Zafra MA, Morales $R$. Low-grade systemic inflammation, hypoadiponectinemia and a high concentration of leptin are present in very young obese children and correlate with metabolic syndrome. Diabetes Metab 2005; 31 : 55-62.

6. Kelesidis T, Mantozoros CS. The emerging role of leptin in humans. Pediatr Endocrinol Rev 2006; 3: 239-248.

7. Collinson A, Moore S, O'Connell M, Charalambos C, Prentice A. Developmental changes in leptin as a measure of energy status in human infants in a natural ecologic setting. Am J Clin Nutr 2005; 81: 488-494.

8. Viso Gonzalez M, Solano L, Sanchez A, Portillo Z, Llovera D. Serum leptin in eutrophic and overweight Venezuelan children and adolescents. Arch Latinoam Nutr 2005; 55: 47-54.

9. Aygun A, Gungor S, Ustung B, Gurgoze M, Sen Y. Proinflamatory cytokines and leptin are increased in serum of prepubertal obese children. Mediators Inflam 2005; 3 : 180-183.

10. Reinehr T, Kratzsch J, Kiess W, Andler W. Circulating soluble leptin receptor, leptin and insulin resistance before and after weight loss in obese children. Int J Obes 2005; 29: 1230-1235.

11. Popruk S, Tungtrongchitr R, Pongpaew P, Phonrat B, Tungtrongchitr $A$, Tribunyatkul $S$, Paksanont $S$, Vudhivai N, Schelp F. Relationship between soluble leptin receptor, leptin, lipid profiles and anthropometric parameters in overweight and obese Thai subjects. J Med Assoc Thai 2005; 88: 220-227.

12. Cinaz $P$, Bideci A, Camurdan M, Guven A, Gonen S. Leptin and soluble leptin receptor levels in obese children in fasting and satiety states. $J$ Pediatr Endocrinol Metab 2005; 18: 303-307. 